\section{Schützen hohe PSA-Werte vor Harnwegsinfektionen?}

B ei Männern, die unter Harnwegsinfektionen (HWI) leiden, wird häufig auch erhöhtes prostataspezifisches Antigen (PSA) im Serum festgestellt. Was meist nur als diagnostische Störung abgetan wird, könnte jedoch einen protektiven Effekt haben. Das PSA ist nicht nur der wichtigste Marker bei der Diagnostik des Prostatakarzinoms, sondern ist auch bei gesunden Männern Bestandteil der Spermienflüssigkeit. Aufgabe der SerinProtease PSA ist es, Proteine wie Semenogelin zu spalten, um das Ejakulat flüssig zu halten. Bei dieser Spaltung entstehen Reste, die antimikrobiell wirken. Zudem enthält Ejakulat WFDC-Proteine („whey-acid motif four-disulphide core"), bei deren Spaltung ebenfalls bakterizide Reste freigesetzt werden. Es wird vermutet, dass so die Spermien vor einer Zersetzung in der Vagina geschützt werden.

Bei einer Auswertung von Patientendaten war britischen Forschern aufgefallen, dass jene HWI-Patienten, bei denen der PSA-Wert bei der ersten HWI nicht erhöht war, signifikant häufiger Rezidive entwickelten. Die Forscher vermuteten daher, dass hohe PSA-Werte Männer vor HWI-Rezidiven schützen. Um ihre Theorie zu bestätigen, untersuchten die Wissenschaftler mittels Realtime-PCR und ELISA, welche Wirkung eine Escherichia-coli-Infektion auf Prostatazelllinien hat. Tatsächlich waren dabei die Gene WFDC2 und SLPI signifikant stärker exprimiert. Wurden die Zellkulturen unter Zugabe von PSA inkubiert, wurde das Wachstum von E. coli signifikant gehemmt. Der Theorie der Forscher zufolge kann demnach mehr PSA mehr antimikrobielle Reste aus den WFDC- und SLPI-Proteinen freisetzen.

Sebastian Lux

\section{Urologische Eingriffe: Antibiotika-Prophylaxe oder nicht?}

Ü: ber das Für und Wider einer antibiotischen Prophylaxe (AP) vor urologischen Operationen wird seit Langem diskutiert. Zwar lassen sich durch den Einsatz von Antibiotika verschiedene Infektionen, darunter Harnweginfektionen (HWI), vermeiden, allerdings steigt auch die Anzahl multiresistenter Erreger (MRE).

Der internationalen GPIU-Studie („global prevalence of infections in urology”) zufolge treten MRE (definiert als resistent gegen drei oder mehr Antibiotika) vor allem in Universitäts- und Lehrkrankenhäusern auf. Patienten, die in den letzten drei Monaten Antibiotika einnahmen, in den letzten sechs Monaten hospitalisiert waren oder einen Ureter- oder suprapubischen Katheter haben, sind demnach besonders HWI-gefährdet. Art des Eingriffs, Vorhandensein von Harnsteinen und Nation spielten keine Rolle.

Eine Möglichkeit, die Anzahl der in der Klinik erworbenen Infektionen mit MRE zu reduzieren, präsentierten japanische Urologen. Im Jahr 2000 begannen sie, in der urologischen Abteilung ihrer Klinik den Antibiotikaverbrauch schrittweise zu reduzieren. Seit 2005 verzichten sie nach Nephrektomien, seit 2007 nach transurethralen Resektionen eines Blasentumors (TURBT) auf jegliche AP. Seit 2007 beschränken sie sich nach einer Prostatektomie oder Zystektomie auf die einmalige orale Gabe von Levofloxazin unmittelbar vor dem Eingriff. Bei Operationen wird - wann immer möglich - auf die gaslose Single-Port-Laparoskopie zurückgegriffen. Bis 2011 konnte so die Anzahl der nosokomialen MREInfektionen signifikant reduziert werden, während diese im selben Zeitraum an der gesamten Klinik zunahmen.

Der Verzicht auf eine AP vor einer perkutanen Nephrolithotomie (PCNL) führt einer Studie zufolge dreimal so häufig zu Infektionen wie eine perioperative AP. Diese Ergebnisse sprechen also für eine flächendeckende Prophylaxe vor PCNL. Bei einer extrakorporalen Stoßwellenlithotripsie (ESWL) hingegen reicht es laut Dr. Kirsten Foell, Toronto, Antibiotika gezielt einzusetzen. Von 526 ESWLPatienten erhielten nur 10 (2,2\%) eine AP, meist aufgrund einer positiven Urinkultur. 14 Patienten bekamen nach der ESWL ein Antibiotikum verschrieben, wenn sie unter Fieber und/oder Symptomen der unteren Harnwege (LUTS) litten. Bei allen 526 Patienten war die HWI-Rate sehr gering $(<1 \%)$.

In einer retrospektiven Kohortenstudie mit über 7.500 Patienten, bei denen eine ambulante Zystoskopie durchgeführt wurde, spielte es keine Rolle, ob Antibiotika verabreicht wurden: 15 Tage nach dem Eingriff hatten nur 0,56\% beziehungsweise $0,41 \%$ der Patienten eine Harnweginfektion, dieser Unterschied war nicht signifikant. Da um eine HWI zu vermeiden 687 Patienten mit Antibiotika behandelt werden müssen, empfahl Poster-Präsentator Dr. Deepak Batura, London, bei Zystoskopien grundsätzlich auf eine Prophylaxe zu verzichten.

Sebastian Lux

\title{
Hier muss der Dummy durch

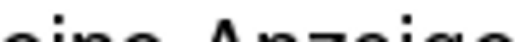

